İş ve İnsan Dergisi | The Journal of Human and Work

Y1l | Year: Ekim | October 2020

Cilt-Sayı | Volume-Issue: 7 (2)

ss I pp: $351-359$

doi: 10.18394/iid.695702

e-ISSN 2148-967X

http://dergipark.gov.tr/iid/

\author{
Araştırma Makalesi
}

\title{
Elektrikli Otomobil Seçiminde Entropi ve TOPSIS Yöntemlerinin Uygulanması
}

\section{Implementation of Entropy and TOPSIS Methods in Electric Car Selection Erdoğan Gavcar ${ }^{a}$, Nusret Kara ${ }^{b}$}

\begin{tabular}{l} 
MAKALE BİLGİSİ \\
\hline Anahtar Kelimeler: \\
Elektrikli Otomobil \\
Entropi, TOPSIS, Çok \\
Kriterli Karar Verme \\
Teknikleri, Performans \\
\hline Tarihler : \\
Geliş 27 Şubat 2020 \\
Düzeltme geliş 01 Mayıs \\
2020 \\
Kabul 24 Haziran 2020
\end{tabular}

\section{ARTICLE INFO}

\section{Keywords:}

Electric Car

Entropy, TOPSIS, Multi

Criteria Decision Making

Methods, Performance.

Article history:

Received 27 February 2020

Received in revised form 01

May 2020

Accepted 24 June 2020
ÖZ

Bu çalışmanın temel amacl, Türkiye'de satışa sunulan 11 farkl model elektrikli otomobilin belirli kriterler baz alınarak karșllaștırılması ve elde ettikleri skora göre siralanmasıdır. Çalı̧̧mada 11 farkl model elektrikli otomobil; batarya kapasiteleri, beygir güçleri, aerodinamik katsayıları, menzilleri ve satıș fiyatları baz alınarak karșılaștırılmıștır. Modellerin belirlenen kriterlere ait gözlem değerleri, firmaların kendi verilerinden elde edilmiştir. Kriterlerin önem düzeyleri Entropi yöntemi kullanılarak belirlenmeye çalıșılmıș ve elde edilen değerler TOPSIS yöntemi ile analiz edilerek otomobillerin karşılaştırması yapılmıştır. Çalışmada elde edilen bulgulara göre, elektrikli otomobillerin beygir gücü ve satış fiyatı kriterleri ön plana çıkmıştır. Karşılaştırma sonucunda Tesla markasının Model X LR ve Model 3 model otomobilleri en yüksek performans skorunu elde etmişlerdir. Bu çalışmanın orijinalliği, otomotiv pazarında kısitll bir paya sahip olan elektrikli otomobillerin karşslaştırılmasının; literatürde diğer çalışmalarda kullanılan beygir gücü ve fiyat kriterlerinin yanı sira menzil, aerodinamik katsayı ve batarya kapasitesi gibi yeni kriterler eklenerek yapılmış olmasındadır.

\begin{abstract}
A B S T R A C T
The main purpose of this study is to compare the 11 different model electric cars offered for sale in Turkey on the basis of certain criteria and to sort them according to the score they obtained. In this study, 11 different models of electric cars compared considering the criteria battery capacities, horsepower, aerodynamic coefficients, ranges and sales prices.The observation values of the models are obtained from the companies' own data. The importance levels of the criteria were determined using Entropy Method and the values obtained were analyzed by TOPSIS method and compared the automobiles. According to the findings of the study, the horsepower and sales price criteria of electric cars came to the fore. As a result of the comparison, the Tesla brand's Model X LR and Model 3 cars achieved the highest performance score. The authenticity of this study is the comparison of electric cars, which have a limited share in the automotive market; In addition to the horsepower and price criteria used in other studies in the literature, new criteria such as range, aerodynamic coefficient and battery capacity are made by adding.
\end{abstract}

a Iletişim kurulacak yazar, Prof. Dr., Muğla Sıtkı Koçman Üniversitesi, İIBF, İşletme Bölümü, Muğla, Türkiye. E-mail:
gavcar@mu.edu.tr. ORCID: O000-0002-2748-3933
b Araş. Gör., Muğla Sıtkı Koçman Üniversitesi, İIBF, Işsletme Bölümü, Muğla, Türkiye. E-mail: nusretkara@mu.edu.tr. ORCID: 00000002-3296-9364 


\section{GİRiș}

Günlük yaşantımızda kararlar alırken farkında olmasak da en iyi kararı almaya çaba gösteririz. Karşı karşıya kaldığımız durumlara göre alternatifler arasından seçim yaparken belirli kriterler altında maksimum faydayı gözetmeye çalışırız. Gerek bireylerin gerekse işletmelerin daha iyi kararlar alması için kriterleri iyi analiz etmesi ve riski hesaplamaları gerekmektedir. Bu yüzden bilim insanları belirli kriterler altında en uygun kararların alınabilmesi için Çok Kriterli Karar Verme Tekniklerini geliştirmişlerdir. Bu teknikler karar vericilere belirsizlik altında optimum kararın verilmesine yardımcı olmayı amaçlamaktadır (Hahn, 2003: 445). Çok Kriterli Karar Verme (ÇKKV) yöntemleri farklı disiplinlerin birlikte çalışmasıyla alınacak kararın her boyutuyla değerlendirilmesini sağlar. ÇKKV yöntemleri karar vermeyi etkileyen kriterlerin optimum noktada buluşmasını sağlayarak mümkün olan en iyi alternatifi seçmeye çalışmak olarak da tanımlanabilir (Turan, 2015: 15).

Günlük yaşantımızda sıklıkla karşılaştığımız karar verme durumlarından birisi de otomobil alırken karşılaştığımız durumlardır. Bir tüketici otomobil almak istediğinde birçok marka ve model içerisinden belirli kriterleri baz alarak en iyi alternatifi seçmeye çalışır. Bu kriterler otomobilin fiyatı, yakıt türü, yakıt tüketimi, motor hacmi, beygir gücü, bagaj hacmi, satış rakamları gibi nicel kriterler olabileceği gibi kalite, renk, tasarım ve prestij gibi nitel kriterlerde olabilir. Birçok kriter arasında en iyi seçimi yapabilmek için kriterlerin önem düzeyleri belirlenmeli ve ÇKKV yöntemlerinden biri kullanılarak analiz edilmelidir.

Son y1llarda tüketicilerin çevreye daha duyarlı hale gelmesi otomobil tercihlerini de etkilemeye başlamıştır. Ayrıca Amerika Birleşik Devletleri ve bazı Avrupa ülkelerinin elektrikli otomobillere sağladığ 1 teşvikler sayesinde tüketiciler giderek bu otomobilleri tercih eder hale gelmiştir. Ülkeler nüfusun artmasıyla oluşacak olan enerji talebini insanları farklı enerji kaynaklarına yönlendirerek denge kurmaya çalışmaktadırlar. Dünya nüfusunun son 50 yılda radikal bir şekilde artması sebebiyle enerji kaynaklarına olan talep giderek artmaktadır. Birleşmiş Milletlerin Raporuna (2019) göre bu yılın ortalarında 7.7 milyara ulaşan nüfusun, 2030 yılında 8.5 milyar, 2050'de 9.7 milyar ve 2100 'de 10.9 milyara ulaşacağı tahmin edilmektedir (World Population Prospects, 2019). Bu artışın su, gıda ve enerji kaynaklarının daha hızlı tüketilmesine sebep olmasının yanı sıra çevreye de olumsuz etkisi bulunmaktadır. Yenilenemez enerji kaynaklarının zaman içinde tükenecek olması ve karbon salınımı nedeniyle çevreye ve insanlara geri dönüşü olmayan zararlar vermesi alternatif enerji kaynaklarının kullanımını zorunlu hale getirmiştir.

Fosil yakıtların kullanımı küresel 1sınmayı arttırmaktadır. Son yüzyılda radikal bir artış gösteren küresel 1sınmanın en önemli nedeni atmosfere salınan sera gazlarıdır. Bu gazlar içinde en önemli olan CO2 gazı salınımı, fosil yakıtlarının yakılması sonucunda oluşmaktadır (Karaalp, 2008). Günlük yaşantımızda sıkça kullandığımız fosil yakıtlı ulaşım araçları açığa çıkardıkları gaz ve taneciklerle soluduğumuz havayı kirletmektedir. Fosil yakıtların kıt olması ve çevreye verdiği zararlardan ötürü sürdürülebilir olmaması insanoğlunu farklı enerji kaynakları arayışına sokmuştur. Son yıllarda çevreye daha az zarar verdiği düşünülen elektrikli araçlar tercih edilmeye başlanmıştır. Elektrikli araç teknolojisi otomobilin icadından beri kullanılan bir teknolojidir. Ancak yüksek üretim maliyetleri ve fosil yakıt kullanan araçların daha güçlü olması ile 1900'lerin başlarından itibaren elektrikli araç kullanımı giderek azalmıştır. Son yıllarda ise petrol fiyatlarının artması ve çevreye verdiği zararların yanısıra bir zaman sonra fosil yakıtların tükenme tehlikesinden dolayı elektrikli araçlar tekrar gündeme gelmiştir. Günümüzde batarya teknolojisinin gelişmesi ve alt yapı çalışmalarının artması elektrikli araç kullanan sayısını arttırmaktadır. Gelişmiş ülkelerin elektrikli araç kullanımını teşvik etmesiyle birlikte gelecek yıllarda elektrikli araçlar daha çok tercih edilecektir. $\mathrm{Bu}$ çalışmada, ele alınan 11 farklı model elektrikli otomobilin batarya, güç, menzil, aerodinamik sürtünme katsayısı (CD) ve fiyat kriterleri baz alınarak kıyaslanması amaçlanmaktadır. Kriterlerin önem düzeyleri (ağırlıkları) objektif olması için Entropi Yöntemi ile belirlenmeye çalışılmıştır. Entropi Yöntemi ile belirlenen ağırlıklar kullanılarak ÇKKV yöntemlerinden biri olan TOPSIS metodu ile gözlem değerleri analiz edilmiş ve alternatifler sıralanmaya çalışılmıştır.

Çalışma beş bölümden oluşmaktadır. İlk bölümde konu hakkında genel bilgiler verilerek çalışmanın amacına değinilmiştir. Çalışmanın ikinci bölümünde literatür taramasına yer verilmiştir. Üçüncü bölümde ise Entropi ve TOPSIS yöntemlerinin metodolojisi anlatılmıştır. Dördüncü bölümde Entropi yöntemiyle kriter ağırlıkları belirlenmiş ve TOPSIS yöntemi ile alternatifler sıralanmıştır. Son bölümde ise bulguların özetlendiği sonuç bölümü yer almaktadır. 


\section{LITERATÜR}

Literatürde, otomobil seçiminin ve sıralanmasının yapıldığı yerli ve yabancı çok sayıda çalışma bulunmaktadır. $\mathrm{Bu}$ çalışmaların çoğu fosil yakıt kullanan otomobiller için yapılmıştır. Yapılan bazı çalışmalara aşağıda yer verilmiştir.

Terzi, Hacaloğlu ve Aladağ (2006), Analitik Hiyerarşi Sürecini (AHP) ve Hedef Programlama yöntemlerini kullanarak otomobil modelleri arasında seçim yapmak amacıyla bir karar destek modeli önermişlerdir. Bu model ile otomobili almak isteyen alıcının beklentileri ve otomobil satmak isteyen satış temsilcisinin bilgisini bir araya getirerek, satın alma işleminin daha etkin hale gelmesini amaçlamaktadırlar.

Ballı, Karasulu ve Korukoğlu (2007) B sınıfina ait 7 farklı otomobil markasını; fiyat, yakıt, performans ve güvenlik kriterlerini baz alarak Bulanık Promethee yöntemi ile analiz edip en uygun markayı seçmiştirler. Çalışmada her bir kritere göre farklı bir marka seçilmiş ve elde edilen sonuçların tutarlı olduğu saptanmıştır.

Soba (2012) çalışmasında Promethee yöntemi ile aynı sınıfa ait 6 farklı panelvan otomobili; fiyat, yakıt, maksimum hız, güvenlik ve beygir gücü kriterlerini baz alarak analiz edip en uygun markayı belirlemiştir. Elde ettiği sonuçlarda en iyi panelvan otomobil Ford Transit Connect Kombi olarak belirlemiştir.

Apak, Göğüş ve Karakadılar (2012) çalışmalarında AHP yöntemini kullanarak tüketicilerin lüks araba tercihlerini etkileyen kriterleri belirlemeye çalışmışlardır. Otomobil satış temsilcileri ile görüşerek kriterlerin ağırlıklarını tespit etmeye çalışmışlardır. Yapılan analiz sonucunda tüketicilerin en çok esneklik ve marka imaj1 kriterlerini önemsediği sonucuna ulaşmışlardır.

Yavuz (2012) çalışmasında öğretmenlerin otomobil tercihlerinde etkili olan faktörleri tespit etmeye çalışmıştır. Performans, ikinci el piyasası, bakım masrafları, yakıt, güvenlik, vergi ve muayene masrafi, bagaj hacmi ve konfor kriterlini temel alarak 6 farklı segment (A, B, C, D, MPV ve LCV) arasından AHP yöntemi ile seçim yapmıştır. Analiz sonucunda öğretmenler için en önemli alternatifin A segmenti araçlar olduğu sonucuna ulaşmıştır.

Şişman ve Eleren (2013) çalışmalarında Gri İlişkisel Analiz ve Electre yöntemlerini kullanarak 11 farklı model arasından en uygun modeli belirlemeye çalışmışlardır. Çalışmada yöntemler birbirlerinden farklı sonuçlar vermiştir. Model yılı, aracın kat ettiği mesafe, fiyat, yakıt tüketimi, bagaj büyüklüğü ve motor gücü gibi nicel kriterlerin yanı sıra yakıt sistemi, şanzıman tipi ve renk gibi nitel kriterler baz alınmıştır.

Sakthivel ve diğerleri (2013) çalışmalarında çok kriterli karar verme yöntemi ile 4 farklı model arasından en uygun otomobili belirlemeye çalışmışlardır. Güvenlik, performans, ekonomik durum, diş tasarım, uygunluk, bayi, garanti ve emisyon değerleri kriterlerinin AHP yöntemi ile ağırlıklarını belirlemişlerdir. Promethee ve Gri İlişkisel Analiz yöntemleri ile iki farklı tercih modeli elde etmişlerdir.

Christopher ve John (2014) çalışmalarında fiyat, konfor, yakıt tüketimi ve dış tasarım kriterlerinin AHP yöntemi ile önem dereceleri belirlenmiştir. Belirlenen ağırlıklara göre 9 farklı model değerlendirilmiştir.

Yavaş, Ersöz, Kabak ve Ersöz (2014) çalışmalarında AHP ve Analitik Ă̆ (ANP) yöntemleri ile tüketicilerin otomobil satın alırken dikkat ettiği kriterlerin önem düzeyleri belirlenmiştir. Otomotiv firmalarının satış danışmanlarıyla yaptıkları görüşmeler sonucunda donanım, tasarım, yakıt türü, motor hacmi, şanzıman türü, fiyat ve satış sonrası hizmet kriterlerini belirlemişlerdir. ANP yöntemine göre tasarım, donanım ve motor hacmi kriterleri daha çok önem arz ederken; AHP yönteminde donanım, tasarım ve yakıt türü kriterlerinin önem düzeyi yüksek çıkmıştır.

Yıldız ve Ergül (2014) çalışmalarında çok kriterli karar verme yöntemlerinden birisi olan Bulanık TOPSIS yöntemi ile 3 farklı otomobil markasının performans değerlendirmesini yapmışlardır. $\mathrm{Bu}$ değerlendirmeyi motor gücü, yakıt tüketimi, satış sonrası hizmet, motor hacmi, fiyat, tasarım ve konfor kriterlerini baz alarak yapmışlardır. Analiz sonucuna en yüksek performansa sahip otomobilin diğerlerine göre daha güçlü, daha rahat, daha estetik ve yakıt tüketiminin daha az olduğunu belirlemişlerdir.

Chand ve Avikal (2015) çalıșmalarında 6 farklı otomobil modelini fiyat, marka, yakıt tüketimi, dış tasarım, satış sonrası servis ve bakım maliyetleri kriterlerini baz alarak AHP yöntemi ile sıralamışlardır.

Roy, Mohanty ve Mohanty (2018) çalışmalarında Bulanık AHP ve Promethee II yöntemlerini kullanarak otomobilleri maliyet, güvenlik ve otomobil sinıfları kriterlerini baz alarak karşılaştırmıştırlar. 
Singh ve Avikal (2019) çalışmalarında Hindistan otomotiv pazarında sedan otomobillerin karşılaştırılmasını Bulanık AHP ve TOPSIS yöntemlerini kullanarak yapmışlardır.

\section{YÖNTEM}

\subsection{Entropi Yöntemi}

Çok kriterli karar verme yöntemlerinde kriterlerin ağırlıklarını belirlemek için çeşitli yöntemler kullanılmaktadır. Bu yöntemlerden birisi de ilk kez Shannon (1949) tarafindan kullanılan Entropi yöntemidir. Shannon finansal yatırımlarda portföy seçiminde entropi metodunu uygulamıştır. Entropi, portföy getirilerinin belirsizliğini ölçmede kullanılmıştır (Huang, 2012: 160). Bir belirsizlik ölçüsü olan entropinin en büyük avantajı kriterlerin veya faktörlerin önem derecelerini belirlerken sadece gözlem değerlerini kullanmasıdır. Bundan dolayı belirlenen ağırlıklar objektif olmaktadır (Chen, Feng \& Chu, 2015: 91). Entropi yönteminin uygulanma adımları aşağıda belirtildiği gibidir ( $\mathrm{Li}$ vd., 2011: 2087)

Adım 1: Karar Matrisinin Normalizasyonu

Gözlem değerlerinin farklı indeks boyutlarını gidermek için fayda ve maliyet özelliklerine göre normalizasyon için kullanılan eşitlik (1)'de yer almaktadır.

$\mathrm{r}_{\mathrm{ij}}=\frac{x_{i j}}{\sum_{i}^{j} x_{i j}}$

Adım 2: Entropi Değerlerinin Hesaplanması

Normalizasyon işleminden sonra kriterlere ait entropi değerleri eşitlik (2) yardımıyla hesaplanır.

$\mathrm{e}_{\mathrm{j}}=-\mathrm{k} \sum_{j=1}^{m} \mathrm{r}_{\mathrm{ij}} \ln \left(\mathrm{r}_{\mathrm{ij}}\right)$

\section{Adım 3: Önem değerlerinin hesaplanması}

Eşitlik (3) yardımıyla kriterlere ait ağırlık katsayıları hesaplanır.

$\mathrm{w}_{\mathrm{j}}=1-\mathrm{e}_{\mathrm{j}} / \sum_{i=1}^{n}\left(1-\mathrm{e}_{\mathrm{j}}\right)$

$\mathrm{Bu}$ adımlardan sonra her bir kritere ait ağırlık katsayısı (wj) belirlenir ve bu katsayıların toplamı daima 1'e eşittir.

\subsection{TOPSIS Yöntemi}

TOPSIS (Technique for Order Preference by Similarity to Ideal Solution) yöntemi Hwang ve Yoon (1981) tarafından geliştirilmiştir. TOPSIS yöntemi ile elde edilecek alternatifinin ideal çözüme yakın olması ve ideal olmayan çözüme uzak olması istenir. İdeal çözüm getiriyi maksimum maliyeti de minimum yapmaya çalışırken ideal olmayan çözüm maliyeti maksimum getiriyi minimum yapmaya çalışır (Chen \& Hwang, 1992; Yoon \& Hwang, 1995). TOPSIS yöntemi basit ve anlaşılır olması kompleks çözümler içermemesinden dolayı çok yaygın olarak kullanılmaktadır. TOPSIS metodunun çözümünde aşağıdaki adımlar izlenir.

\section{Adım 1: Karar Matrisinin Oluşturulması}

Karar verici tarafindan $m^{*} n$ boyutlu kriterlerin ve onlara ait gözlem değerlerinin olduğu bir matris oluşturulur. Başlangıç matrisi olarak da adlandırılan bu matris eşitlik (4) de gösterildiği gibidir.

$\mathrm{A}_{\mathrm{ij}}=\left[\begin{array}{lll}a_{11} & a_{21} & a_{31} \\ a_{21} & a_{22} & a_{32} \\ a_{31} & a_{23} & a_{33}\end{array}\right]$

Adım 2: Normalize Matrisinin Elde Edilmesi

Karar matrisi oluşturulduktan eşitlik (5) yardımıyla normalizasyon işlemi gerçekleştirilir.

$\mathrm{n}_{\mathrm{ij}}=\frac{\mathrm{a}_{\mathrm{ij}}}{\sqrt{\sum_{\mathrm{i}=1}^{\mathrm{m}} \mathrm{a}_{\mathrm{ij}}^{2}}}$

Adım 3: Ă̆ırlıklandırılmış Normalize Matrisin Elde Edilmesi

Normalize edilmiş her bir değer wi gibi bir değerle çarpılır. Bu işlemde dikkat edilmesi gereken nokta wi değerlerinin toplamının 1' eşit olmasıdır.

Adım 4: İdeal ve İdeal Olmayan Çözüm Değerlerinin Elde Edilmesi

Ağırlıklandırılmış normalize matris elde edildikten sonra eşitlik (6) ve (7) yardımıyla ideal olan ve olmayan çözüm değerleri elde edilir.

$A^{+}=\left\{\left(\operatorname{maxv}_{i j} \mid j=1, \ldots, p ; j=1, \ldots . ., m\right\}\right.$ 
$A^{-}=\left\{\left(\operatorname{minv}_{i j} \mid j=1, \ldots, p ; i=1, \ldots \ldots, m\right\}\right.$

Adım 5: Alternatifler Arasindaki Mesafelerin Ölçülmesi

İdeal olan ve olmayan noktalar arasındaki uzaklık eşitlik (8) ve (9) yardımıyla hesaplanır.

$\mathrm{S}^{+}=\sqrt{\sum_{j=1}^{n}\left(v_{i j}-v_{j}^{+}\right)^{2}}$

$\mathrm{S}^{-}=\sqrt{\sum_{j=1}^{n}\left(v_{i j}-v_{j}^{-}\right)^{2}}$

Adım 6: İdeal Çözüme Göreli Yakınlığın Hesaplanmasl

Her bir karar noktasının ideal çözüme olan göreli yakınlığın hesaplanmasında eşitlik (10) kullanılır.

$C_{i}^{*}=\frac{S_{i}^{-}}{S_{i}^{-}+S_{i}^{+}}$

$\mathrm{C}_{\mathrm{i}}{ }^{*}$ değeri $[0,1]$ arasında bir değer alır. Değer 1'e yaklaştığında ideal çözüme yaklaşılır, 0'a yaklaştığında ise ideal olmayan çözüme yaklaşılır.

\section{UYGULAMA}

Çalışmanın bu bölümünde 11 farklı model elektrikli otomobil arasından "batarya", "güç", "aerodinamik sürtünme katsayısı", "menzil" ve "fiyat" kriterleri baz alınarak en iyi modelin belirlenmesi amaçlanmaktadır. 11 farklı model elektrikli otomobiller ve kriterlere ait gözlem değerleri Tablo 1' de gösterilmiştir. Kriterleri belirlenirken daha önce yapılmış çalışmalarda en fazla kullanılan fiyat ve motor gücü kriterleri bu çalışmada da kullanılmıștır. Çalışma elektrikli otomobiller üzerine olduğu için batarya gücü, tam dolu şarjla gidebileceği maksimum mesafe (menzil) ve aerodinamik sürtünme katsayısı (CD) kriterlerinin karar vermede etkin rol oynayacağı düşünülerek ilgili kriterler çalışmaya eklenmiştir. Çalışmada batarya kapasitesi kriterinin birimi kilowatt saat, güç kriterinin birimi beygir, menzil kriterinin birimi kilometre ve fiyat kriterinin birimi Amerikan Doları alınarak analize dahil edilmiştir. CD kriterinin ise tanımı gereği birimi yoktur. Kriterlere ait gözlem değerleri firmaların kendi internet sitelerinden ve otomobillerin kataloglarından elde edilmiştir (bkz. Tablo 1).

Otomobil firmalarının sitelerinden ve kataloglarından elde edilen verilerle Tablo 1'deki karar matrisi oluşturulmuştur. Kriterlere ait ağırlık katsayılar Entropi yöntemi ile belirlenmeye çalışılacaktır. Bunun için ilk olarak tablo 1'deki karar matrisinin normalizasyonu eşitlik (1)'deki gibi hesaplanıp Tablo 2'de gösterilmiştir (bkz. Tablo 2).

Karar matrisinin normalizasyonundan sonra her bir kritere ait entropi değerlerinin hesaplanması için eşitlik (2) kullanılmıştır. Eşitliğe göre; her bir değerin doğal logaritması alınır ve kendi değeri ile çarpılır. Daha sonra entropi katsayısı (k) değeri eşitlik (11) kullanılarak hesaplanmıştır. Eşitlik (2) yardımıyla Entropi değerleri (ej) hesaplanmıştır. Ej değerleri 1'den çıkarılarak (1-ej) değerleri bulunmuştur. Elde edilen sonuçlar Tablo 3'de gösterilmiștir (bkz. Tablo 3).

Tablo 1: Çalıșmada Kullanılan Gözlem Değerleri

\begin{tabular}{lccccc}
\hline Otomobil & Batarya & Güç & CD & Menzil & Fiyat \\
\hline Audi E-Tron & 87 & 402 & 0,28 & 436 & 77.700 \\
Tesla Model X LR & 97 & 780 & 0,24 & 507 & 68.000 \\
Porsche Taycan Turbo S & 84 & 750 & 0,25 & 450 & 173.000 \\
MG ZS EV & 44 & 143 & 0,24 & 262 & 28.000 \\
Polestar 2 & 75 & 408 & 0,26 & 490 & 55.000 \\
DS3 E-Tense & 47 & 136 & 0,27 & 320 & 36.800 \\
Nissan Leaf e+ & 56 & 218 & 0,28 & 385 & 42.000 \\
Opel Corsa-e & 47 & 136 & 0,29 & 330 & 28.000 \\
Kia Niro & 64 & 204 & 0,3 & 455 & 36.500 \\
Tesla Model 3 & 74 & 577 & 0,23 & 530 & 57.000 \\
Kona & 64 & 204 & 0,29 & 470 & 38.500 \\
\hline
\end{tabular}


Tablo 2: Karar Matrisinin Normalizasyonu

\begin{tabular}{lccccc}
\hline \multicolumn{1}{c}{ Araç } & Batarya & Güç & CD & Menzil & Fiyat \\
\hline Audi E-Tron & 0,1177 & 0,1016 & 0,0956 & 0,0941 & 0,1213 \\
Tesla Model X LR & 0,1313 & 0,1971 & 0,0819 & 0,1094 & 0,1062 \\
Porsche Taycan Turbo S & 0,1137 & 0,1895 & 0,0853 & 0,0971 & 0,2701 \\
MG ZS EV & 0,0595 & 0,0361 & 0,0819 & 0,0565 & 0,0437 \\
Polestar 2 & 0,1015 & 0,1031 & 0,0887 & 0,1057 & 0,0859 \\
DS3 E-Tense & 0,0636 & 0,0344 & 0,0922 & 0,0690 & 0,0575 \\
Nissan Leaf e+ & 0,0758 & 0,0551 & 0,0956 & 0,0831 & 0,0656 \\
Opel Corsa-e & 0,0636 & 0,0344 & 0,0990 & 0,0712 & 0,0437 \\
Kia Niro & 0,0866 & 0,0515 & 0,1024 & 0,0982 & 0,0570 \\
Tesla Model 3 & 0,1001 & 0,1458 & 0,0785 & 0,1143 & 0,0890 \\
Kona & 0,0866 & 0,0515 & 0,0990 & 0,1014 & 0,0601 \\
\hline
\end{tabular}

Tablo 3: Entropi Değerleri

\begin{tabular}{lccccc}
\hline \multicolumn{1}{c}{ Otomobil } & Batarya & Güc & CD & Menzil & Fiyat \\
\hline Audi E-Tron & $-0,2519$ & $-0,2323$ & $-0,2244$ & $-0,2224$ & $-0,2559$ \\
Tesla Model X LR & $-0,2665$ & $-0,3201$ & $-0,2050$ & $-0,2421$ & $-0,2381$ \\
Porsche Taycan Turbo S & $-0,2472$ & $-0,3152$ & $-0,2100$ & $-0,2264$ & $-0,3536$ \\
MG ZS EV & $-0,1680$ & $-0,1200$ & $-0,2050$ & $-0,1624$ & $-0,1368$ \\
Polestar 2 & $-0,2322$ & $-0,2342$ & $-0,2149$ & $-0,2375$ & $-0,2108$ \\
DS3 E-Tense & $-0,1752$ & $-0,1158$ & $-0,2197$ & $-0,1845$ & $-0,1641$ \\
Nissan Leaf e+ & $-0,1955$ & $-0,1597$ & $-0,2244$ & $-0,2067$ & $-0,1787$ \\
Opel Corsa-e & $-0,1752$ & $-0,1158$ & $-0,2289$ & $-0,1881$ & $-0,1368$ \\
Kia Niro & $-0,2119$ & $-0,1528$ & $-0,2333$ & $-0,2279$ & $-0,1633$ \\
Tesla Model 3 & $-0,2304$ & $-0,2807$ & $-0,1998$ & $-0,2480$ & $-0,2153$ \\
Kona & $-0,2119$ & $-0,1528$ & $-0,2289$ & $-0,2321$ & $-0,1690$ \\
\multicolumn{1}{c}{ Toplam } & $\mathbf{- 2 , 3 6 5 8}$ & $\mathbf{- 2 , 1 9 9 5}$ & $\mathbf{- 2 , 3 9 4 2}$ & $\mathbf{- 2 , 3 7 8 0}$ & $\mathbf{- 2 , 2 2 2 4}$ \\
$\quad \mathbf{E}_{\mathbf{j}}$ & $\mathbf{0 , 9 8 6 6}$ & $\mathbf{0 , 9 1 7 3}$ & $\mathbf{0 , 9 9 8 5}$ & $\mathbf{0 , 9 9 1 7}$ & $\mathbf{0 , 9 2 6 8}$ \\
$\quad\left(\mathbf{1}-\mathbf{E}_{\mathbf{j}}\right)$ & $\mathbf{0 , 0 1 3 4}$ & $\mathbf{0 , 0 8 2 7}$ & $\mathbf{0 , 0 0 1 5}$ & $\mathbf{0 , 0 0 8 3}$ & $\mathbf{0 , 0 7 3 2}$ \\
\hline
\end{tabular}

$\left.\mathrm{k}=[\ln (\mathrm{n})]^{-1} \quad \mathrm{n}=11\right)$

Son olarak eşitlik (3) kullanılarak tüm kriterlere ait ağırlık katsayıları (wj) hesaplanır. Elde edilen wj değerleri Tablo 4'te gösterilmiștir (bkz. Tablo 4).

Entropi yöntemi ile elde edilen sonuçlara göre otomobillerin motor gücü $(w 2=0,4619)$ ve fiyatı (w5=0,4087) ÇKKV teknikleri ile yapilacak kıyaslamalarda çok fazla önem arz etmektedir. Kriterler arasinda en az öneme sahip olan ise aerodinamik katsayı $(\mathrm{CD})$ kriteridir $(\mathrm{w} 3=0,0085)$ (bkz. Tablo 5).

Kriterlerin ağırlık katsayıları belirlendikten sonra alternatiflerin kıyaslanması için ÇKKV tekniklerinden TOPSIS metodu uygulanmıştır. Tablo 5'te TOPSIS yönteminin ilk adımı olan karar matrisi yer almaktadır. Matrisin en alt satırında her bir kriterin ağırlık değerleri bulunmaktadır. TOPSIS yönteminin adımları uygulanırken "batarya", "güç" ve "menzil" kriterlerinin maksimum, "CD" ve "fiyat" kriterlerinin ise minimum olması istenmiștir. Elde edilen TOPSIS çözümü Tablo $6^{\prime}$ da gösterilmiştir (bkz. Tablo 6).

\section{SONUÇ}

1900'lü yılların başında kullanılmaya başlanan daha sonra terkedilen elektrikli araçlar batarya ve pil teknolojisinde yaşanan gelişmelerden sonra tekrar tüketicilerin kullanıma sunulmuştur. Elektrikli 
Tablo 4: Kriterlerin Ağırlık Katsayıları

\begin{tabular}{cccccc}
\hline Otomobil & Batarya & Güç & CD & Menzil & Fiyat \\
\hline $\mathrm{W}_{\mathrm{j}}$ & 0,0746 & 0,4619 & 0,0085 & 0,0463 & 0,4087 \\
\hline
\end{tabular}

Tablo 5: Karar Matrisi

\begin{tabular}{lccccc}
\hline \multicolumn{1}{c}{ Otomobil } & Batarya & Güç & CD & Menzil & Fiyat \\
\hline Audi E-Tron & 87 & 402 & 0,28 & 436 & 77.700 \\
Tesla Model X LR & 97 & 780 & 0,24 & 507 & 68.000 \\
Porsche Taycan Turbo S & 84 & 750 & 0,25 & 450 & 173.000 \\
MG ZS EV & 44 & 143 & 0,24 & 262 & 28.000 \\
Polestar 2 & 75 & 408 & 0,26 & 490 & 55.000 \\
DS3 E-Tense & 47 & 136 & 0,27 & 320 & 36.800 \\
Nissan Leaf e+ & 56 & 218 & 0,28 & 385 & 42.000 \\
Opel Corsa-e & 47 & 136 & 0,29 & 330 & 28.000 \\
Kia Niro & 64 & 204 & 0,3 & 455 & 36.500 \\
Tesla Model 3 & 74 & 577 & 0,23 & 530 & 57.000 \\
Kona & 64 & 204 & 0,29 & 470 & 38.500 \\
& $\mathbf{0 , 0 7 4 6}$ & $\mathbf{0 , 4 6 1 9}$ & $\mathbf{0 , 0 0 8 5}$ & $\mathbf{0 , 0 4 6 3}$ & $\mathbf{0 , 4 0 8 7}$ \\
\hline
\end{tabular}

araçlara yapılan teşvikler de tüketicilerin bu araçları tercih etmelerinde etkili olmasına rağmen elektrikli otomobil satışları hala istenilen düzeyde değildir. 2019 yılı ortalarına kadar Dünya genelinde satılan her 100 otomobilden sadece 2'si elektrikli otomobildir (Global EV Outlook, 2019). Türkiye'de ise elektrikli otomobillerin pazar payı Dünya ortalamasının çok altındadır. Otomotiv Distribütörleri Derneği'nin (ODD) raporuna göre (2019) Türkiye'de 2019 yılı içinde 222 adet elektrikli otomobil satılmıştır. $\mathrm{Bu}$ satış adedi ile birlikte elektrikli otomobillerin toplam satışlar içinde \%0.06'lik bir paya sahip olduğu anlaşılmaktadır (ODD, 2019). Elektrikli otomobil satışlarının bu kadar düşük olması; sürücülerin bu teknolojiye alışamamaları, dar bir ürün seçeneğinin olması, fiyatlarının fosil yakıtlı araçlara göre daha pahalı olması ve bataryalarının kullanıldıkça güçlerini kaybetmeleri gibi nedenlerle açıklanabilir. $\mathrm{Bu}$ çalışmada Türkiye'de satılan elektrikli otomobillerin belirtilen kriterler baz alınarak kıyaslanması yapılmıştır. Bu çalışmada herhangi bir marka veya modelin ön plana çıkarılması amaçlanmamış ve herhangi bir yönlendirme yapılmamıştır. Analizlerde kullanılan veriler firmaların tüketicilerle paylaştığ Kriterlerin ağırlıklarının belirlenmesi de objektif olması açısından Entropi metodu ile hesaplanmıştır.

Elde edilen sonuçlara göre en yüksek performans skoru Tesla Model X LR modeline aittir. Modelin satış fiyatına göre alternatifler arasında en pahalı 3 .

Tablo 6: TOPSIS Yöntemi Sonuçları

\begin{tabular}{lcc}
\hline \multicolumn{1}{c}{ Otomobil } & Skor & Siralama \\
\hline Tesla Model X LR & 0,7596 & 1 \\
Tesla Model 3 & 0,6461 & 2 \\
Porsche Taycan Turbo S & 0,5598 & 3 \\
Audi E-Tron & 0,4508 & 4 \\
Polestar 2 & 0,4373 & 5 \\
Nissan Leaf e+ & 0,1655 & 6 \\
Kona & 0,1384 & 7 \\
Kia Niro & 0,1302 & 8 \\
DS3 E-Tense & 0,0689 & 9 \\
Opel Corsa-e & 0,0117 & 10 \\
MG ZS EV & 0,0108 & 11 \\
\hline
\end{tabular}


Model olmasına rağmen alternatifler arasında sahip olduğu beygir gücü, menzil ve batarya kapasitesi ile en yüksek skoru elde etmiştir. İkinci en yüksek skor ise Tesla Model 3 modeline aittir. Otomobilin kriterleri incelendiğinde ortalamanın üstünde güç, menzil ve batarya kapasitesini ortalamanın altında bir fiyata sunmaktadır. En ucuz satış fiyatına sahip iki modelin (Opel Corsa-e ve MGZS EV) en düşük skorları elde etmesinde ortalamanın çok altında güç, menzil ve batarya kapasitelerine sahip olmaları etkili olmuştur.

Literatürde ÇKKV teknikleri kullanılarak otomobillerin kıyaslanması çok çalışılmış bir konu olmasına rağmen elektrikli otomobillere ait kıyaslama yapılmamıştır. Ayrıca alternatifler elektrikli otomobiller olduğu için kullanılan kriterlerde daha önceki çalışmalarda kullanılan kriterlerden farkl1lık göstermektedir.

Elektrikli otomobiller yaygınlaştıkça bu tür karşılaştırmalar yeni kriterler eşliğinde yapılarak daha nitelikli sonuçlar ortaya çıkacaktır. Ayrıca kriterlerin ağırlıkları farklı yöntemlerle belirlenip benzer çalışmalarının yapılıp sonuçların karşılaştırılması literatüre katkı sağlayacaktır.

\section{ETİK BEYANATI}

Destek Bilgisi: $\mathrm{Bu}$ çalışma, kamu, ticari veya kar amacı gütmeyen kuruluşlar gibi herhangi bir organizasyondan destek almamıştır.

Çıkar Çatışması: Tüm yazarlar adına, sorumlu yazar çıkar çatışması olmadığını belirtir.

Etik Onayı: $\mathrm{Bu}$ çalışmada gerçekleştirilen tüm prosedürler, kurumsal ve / veya ulusal araştırma komitesinin etik standartlarına ve 1964 Helsinki deklarasyonuna ve daha sonraki değişikliklerine veya karşılaştırılabilir etik standartlara uygundur.

\section{KAYNAKÇA}

Apak, S., Göğüş, G. G. \& Karakadılar, İ. S. (2012). An analytic hierarchy process approach with a novel frame work for luxury car selection. ProcediaSocialand Behavioral Sciences, 58, 1301- 1308.

Ballı S., Karasulu B. \& Korukoğlu S. (2007). En Uygun Otomobil Seçimi Problemi İçin Bir Bulanık Promethee Yöntemi Uygulamas1. D.E.Ü.I.I.B.F Dergisi, 22(1), 139-147

Chand, M. \& Avikal, S. (2015). An MCDM based approach for purchasing a car from Indian car market. 2015 IEEE Students Conference on Engineering and Systems (SCES), Allahabad, India.

Chen, S. J. \& Hwang, C. L. (1992). Fuzzy multiple attribute decision making: Methods and applications. Berlin: Springer-Verlag.

Chen, W., Feng, D. \& Chu, X. (2015). Study of Poverty Alleviation Effects for Chinese Fourteen Contiguous Destitute Areas Based on Entropy Method. International Journal of Economics and Finance, 7(4), 89-98.

Christopher, T. \& John, J. S. (2014). Multi criteria Decision Technique on Product Prioritization. International Journal of Emerging Engineering Research and Technology, 2(3), 194-200.

Global EV Outlook Technology Report (2019). Ylllık Rapor. Erişim Tarihi: 15.01.2020

Hahn E. D. (2003). Decision Making With Uncertain Judgements: A Stochastic Formulation Of The Analytic Hierarchy Process. Decision Sciences, 34(3), 444[p1]-486.

Huang, X. (2012). An Entropy Method for Diversified Fuzzy Portfolio Selection. International Journal of Fuzzy Systems, 14(1), 160-165.

Hwang, C. L. \& Yoon, K. (1981). Multiple Attribute Decision Making: Methods and Applications. Springer-Verlag, New York.

Karaalp, H. S. (2008). Sektörel açıdan İklim Değişikliğgi: Tarım, Ulaştırma ve Sanayi”. Küresel Isınma ve Kyoto Protokolü İklim Değişikliğinin Bilimsel, Ekonomik ve Politik Analizi, (der. E. Karakaya), İstanbul: Bağlam Yayıncılık. , s. 286.

Li, X., Wang, K., Liu, L., Xin, J., Yang, H. \& Gao, C. (2011). Application of the entropy weight and TOPSIS method in safety evaluation of coal mines. Procedia Engineering, 26, 2085-2091.

Otomotiv Distribütörleri Derneği (ODD). (2019). Yıllık rapor. 15 Ocak 2020, http://www.odd.org.tr. 
Roy, S., Mohanty, S. \& Mohanty, S. (2018, August). An Efficient Hybrid MCDM Based Approach for Car Selection in Automobile Industry. In 2018 International Conference on Research in Intelligent and Computing in Engineering (RICE), 1-5.

Sakthıvel, G., Ilangkumaran, M., Nagarajan, G., Raja, A., Ragunadhan, P., M. \& Prakash, J. (2013). A hybrid MCDM approach for evaluating an automobile purchase model. Int. J. Information and Decision Sciences, 5(1), $50-85$.

Shannon, C. E. (1949). The Mathematical Theory of Communication. The University of Illinois Press, Urbana.

Singh, R., \& Avikal, S. (2019). A MCDM-Based Approach for Selection of a Sedan Car from Indian Car Market. In Harmony Search and Nature Inspired Optimization Algorithms. Yadav N., Yadav A., Bansal J., Deep K. \& Kim J. (eds) (pp. 569-578). Springer, Singapore[p3].

Soba, M. (2012). Promethee Yöntemi Kullanarak En Uygun Panelvan Otomobil Seçimi Ve Bir Uygulama. Journal of Yasar University, 28(7), 4708- 4721.

Şişman, B. \& Eleren, A. (2013). En Uygun Otomobilin Gri İlişkisel Analiz Ve Electre Yöntemleri İle Seçimi. Süleyman Demirel Üniversitesi, Íktisadi ve İdari Bilimler Fakültesi Dergisi,18(3), 411-429.

Terzi, Ü., Hacaloğlu, S., E. \& Aladağ, Z. (2006). Otomobil Satın Alma Problemi İçin Bir Karar Destek Modeli. Ístanbul Ticaret Üniversitesi Fen Bilimleri Dergisi, 5(10), 2006/2, 43-49.

Turan, G. (2015). Çok Kriterli Karar Verme Yöntemleri. Bursa: Dora Kitap.

United Nations (UN). (2019). Y1llık Rapor. 25.01.2020. www.un.org.en

World Population Prospects (WPP). (2019). Y1llik rapor. 15.01.2020. www.population.un.org.

Yavaş, M., Ersöz, T., Kabak, M. \& Ersöz, F. (2014). Otomobil Seçimine Çok Kriterli Yaklaşım Önerisi. İşletme ve İktisat Çalışmaları Dergisi, 2(4), 110-118.

Yavuz, S. (2012). Öğretmenlerin Otomobil Tercihlerinde Etkili Olan Faktörlerin Analitik Hiyerarşi Yöntemiyle Belirlenmesi. Erzincan Üniversitesi IIBBF Dergisi, 32(2), 29-46.

Yıldız, A. \& Ergül, E., U. (2014). Usage of Fuzzy Multicriteria Decision Making Method to Solve the Automobile Selection Problem. Journal of Engineering and Fundamentals (JEF), 1(1), 1-10.

Yoon, K. P. \& Hwang, C. L. (1995). Multiple attribute decision making. Thousand Oaks, CA: Sage Publication. 